Portland State University

PDXScholar

6-1-1995

\title{
Clinical Application of Two Phonological-based Treatment Approaches
}

Holly Kiesz Royer

Portland State University

Follow this and additional works at: https://pdxscholar.library.pdx.edu/open_access_etds

Part of the Speech and Rhetorical Studies Commons

Let us know how access to this document benefits you.

Recommended Citation

Royer, Holly Kiesz, "Clinical Application of Two Phonological-based Treatment Approaches" (1995). Dissertations and Theses. Paper 5196.

https://doi.org/10.15760/etd.7072

This Thesis is brought to you for free and open access. It has been accepted for inclusion in Dissertations and Theses by an authorized administrator of PDXScholar. Please contact us if we can make this document more accessible: pdxscholar@pdx.edu. 


\section{THESIS APPROVAL}

The abstract and thesis of Holly Kiesz Royer for the Master of Science in Speech Communication: Speech and Hearing Sciences were presented June 1, 1995, and accepted by the thesis committee and the department.

COMMTTEE APPROVALS:
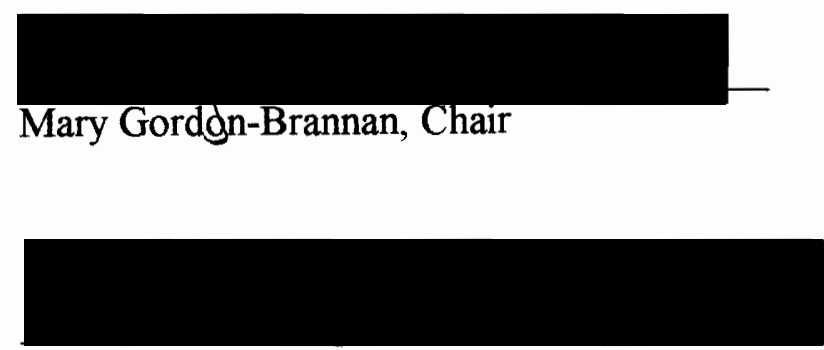

Ellen Reuler



Representative, Office of Graduate Studies

DEPARTMENT APPROVAL:

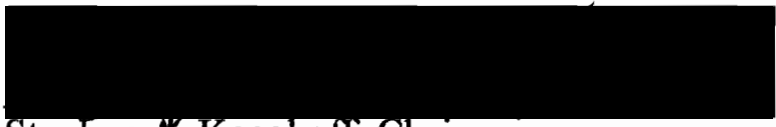

Stephen A. Kosokoff, Chair

Department of Speech Communication

\section{$* * * * * * * * * * * * * * * * * * * * * * * * * * * * * * * * * * * * * * * * * * * * * * * * * * * * * * * * * * * * * * * * * * * * * * * *$}

ACCEPTED FOR PORTLAND STATE UNIVERSITY BY THE LIBRARY

by

on

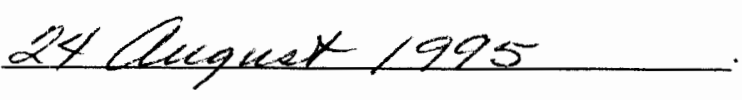




\begin{abstract}
An abstract for the thesis of Holly Kiesz Royer for the Master of Science in Speech Communication: Speech and Hearing Sciences presented June 1, 1995.
\end{abstract}

Title: Clinical Application of Two Phonological-Based Treatment Approaches.

This single-subject study was designed to compare the effectiveness of two phonological-based treatment approaches with a preschool male with unintelligible speech characterized by multiple deficient phonological patterns. Four phonological patterns were chosen as targets based on results of the Assessment of Phonological ProcessesRevised (APP-R) (Hodson, 1986), as analyzed by the Computer Analysis of Phonological Deviation (CAPD) (Hodson, 1992a). The subject participated in 60-minute intervention sessions three times a week over an 8-week period. The phonological cycling approach (Hodson \& Paden, 1991) was the focus of 4 weeks of intervention, and the minimal pairs approach (Tyler, Edwards, \& Saxman, 1987) was the focus of 4 weeks of intervention. Remediation programs were alternated every 2 weeks, and began with the phonological cycling approach. Results were measured through pretests and posttests of the APP-R, as well as baseline and generalization probes that were administered periodically.

Results of the CAPD indicated minimal changes between pretest and posttest scores for all of this subject's targeted phonological patterns (i.e., consonant sequences / stridents, velars, liquid $/ \mathrm{L}$, and liquid $/ \mathrm{r} /$ ). In addition, no significant differences in scores were noted between remediation programs. Results of probe measurements indicated little, if any, generalization to targeted and non-targeted words in an imitated word probe task for any of the targeted patterns, except for the target phonological pattern of consonant sequences / stridents after the phonological cycling approach. This finding may suggest that the phonological cycling approach was more effective for this subject than the minimal pairs approach. 


\title{
CLINICAL APPLICATION OF TWO PHONOLOGICAL- BASED TREATMENT APPROACHES
}

\author{
by \\ HOLLY KIESZ ROYER
}

A thesis submitted in partial fulfilment of the

requirements for the degree of

\author{
MASTER OF SCIENCE \\ in \\ SPEECH COMMUNICATION: \\ SPEECH AND HEARING SCIENCES
}

Portland State University

1995 


\section{ACKNOWLEDGMENTS}

First and foremost, I would like to thank my husband for supporting this endeavor, and for spending so many hours helping me on the computer with my thesis graphs and tables. Your love and patience has meant so much to me!

I would like to take this opportunity to thank the faculty of the Speech and Hearing Sciences program for the learning experience they've provided me for the past three years. Many thanks go to my thesis committee members, Ellen Reuler and Marjorie Terdal for their time and energy. I would also like to especially thank Mary GordonBrannan, my academic and thesis advisor, for taking the time to answer my many questions and for helping to push me through with my thesis in those last few weeks!

Finally, I would like to thank all the students who have endured with me throughout these last few years. You have encouraged my in so many ways and I have enjoyed working with all of you - especially Megan, Anne, and Julie. Good luck with your careers! 


\section{TABLE OF CONTENTS}

PAGE

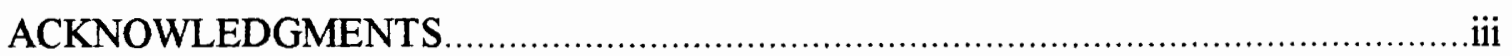

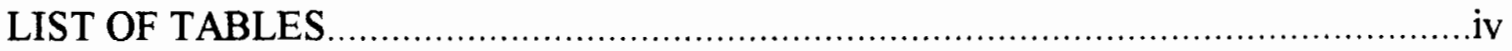

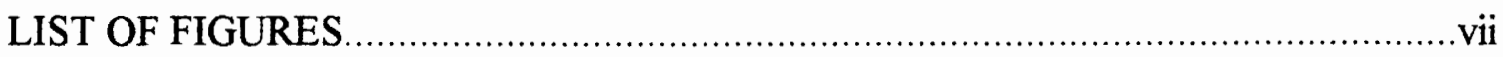

CHAPTER

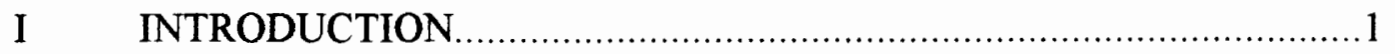

Statement of Purpose................................................ 2

Definition of Terms ....................................................... 2

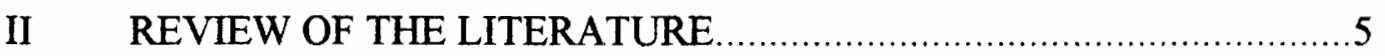

Phonological Cycling Approach........................................6

Concepts and Procedures......................................6

Efficacy .....................................................

Contrasting Pairs Approach............................................. 9

Concepts and Procedures....................................... 9

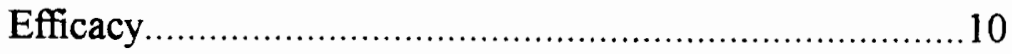

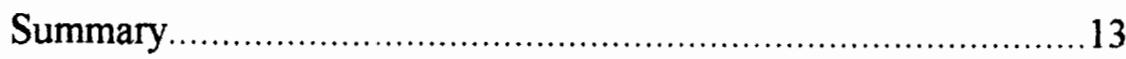

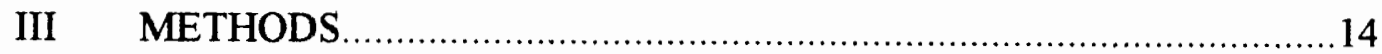

Subject................................................................... 14

Procedures.................................................................... 15

Experimental Design............................................15

Pre- and Post-Test Measures.....................................17 
T

Target Selection............................................. 17

Treatment Procedures......................................... 18

Data Measurement and Analysis.....................................22

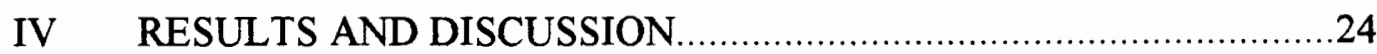

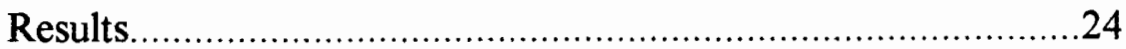

Pre- and Post-Test Measures....................................24

Phonological Cycling Approach.............................26

Minimal Pairs Approach....................................27

Baseline and Probes...............................................27



Pre- and Post-Test Measures...................................34

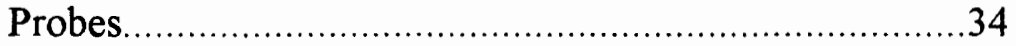

Summary ......................................................... 37

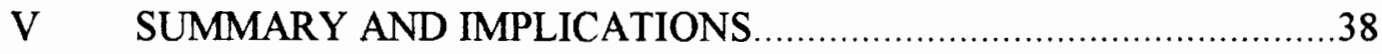



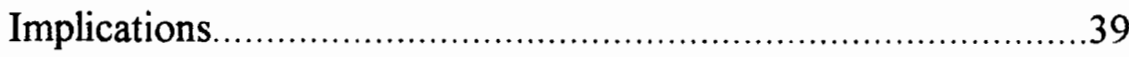

Clinical Implications............................................39

Research Implications..........................................40

REFERENCES.................................................................4

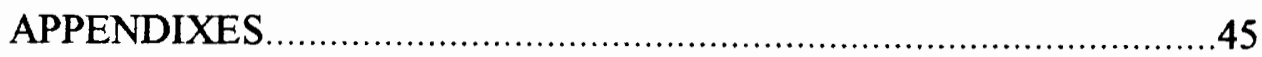




\section{LIST OF TABLES}

TABLE

PAGE

$1 \quad$ APP-R Percentage of Occurrence Summary (Pretest) ....................... 16

2 Phonological Analysis Summary of the APP-R ............................25

3 Cycles and Training Targets for Phonological Cycling Approach...........27

4 Results of Minimal Pairs Approach with Velars by Session..................28

5 Results of Minimal Pairs Approach with Liquid / $/$ by Session................29 


\section{LIST OF FIGURES}

FIGURES

PAGE

$1 \quad$ Flow Chart of Treatment Procedures.................................................19

2 Flow Chart of Phonological Cycling Approach.................................20

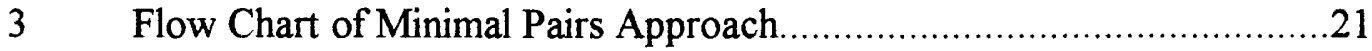

4 Percentage of Correct Production of Consonant Sequences / Sridents.....31

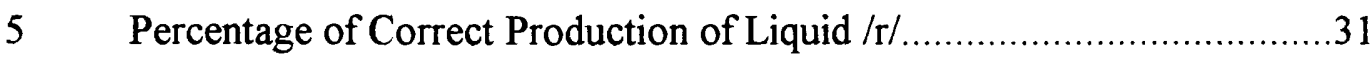

$6 \quad$ Percentage of Correct Production of Velars.........................................31

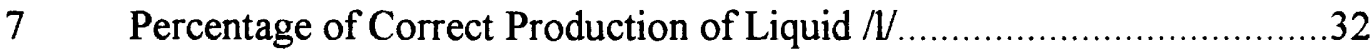

$8 \quad$ Percentage of Correct Production of Glides......................................32 


\section{CHAPTER I}

\section{INTRODUCTION}

For the past two decades, researchers and clinicians have embraced a broader concept of phonology that includes articulation as a part of a child's expressive language system (Hodson, 1992b). Phonology encompasses both the articulation of sounds and the knowledge of the sound system and sound patterns (Weiss, Gordon, \& Lillywhite, 1987). In some arenas, the term phonological disorder has replaced the traditional term, articulation disorder. A phonological disorder is considered to be the result of a child's systematic application of phonological rules or processes (systematic sound changes affecting entire classes of sounds or sound sequences) (Saben \& Ingham, 1991).

Knowledge of how a normal phonological system is acquired has helped in developing an understanding of disordered phonology. A phonological process describes the child's systematic modifications that result from the common difficulty a class of sounds or sound sequences creates for the speech capacity (Tyler, Edwards, \& Saxman, 1987). These processes allow children to make adult words pronounceable and enable them to produce an approximation of an adult model. As children develop, that system is revised through suppression of these phonological processes and adult sound patterns are used (Weiner, 1981).

Through a phonological assessment, a child's systematic speech sound error patterns can be revealed. For the past few years, several procedures have been described that use the results of phonological assessment in treating the misarticulations of children with functional articulation disorders. A treatment approach based on phonological assessment involves facilitating the emergence of new sound patterns through targeting deficient phonological patterns, as opposed to treating separate sound errors (Tyler et al., 1987). 
Targeting these patterns provides the clinician an opportunity to add greater efficiency to the clinical process. By eliminating a few specific sound errors, changes in the underlying pattern accounting for those errors can be seen (Weiner, 1981). In other words, remediation is maximized through generalization that occurs across the sounds affected by a particular pattern when only a few sounds are taught. Therefore, other errors emerging from the pattern may also be eliminated without direct training (Tyler et al., 1987). Although advocates of a phonological-based treatment approach argue that it is efficient and effective, this has yet to be established through empirical clinical studies.

\section{Statement of Purpose}

This study was designed to compare the effectiveness of two phonological-based treatment approaches with a preschool child with unintelligible speech, that is, the phonological cycling approach developed by Hodson and Paden (1991) and the minimal pairs approach as outlined by Tyler et al. (1987). The corresponding research question for this study was: Is there a significant difference between the phonological cycling approach and the minimal pairs approach as determined by a decrease of 10 percentage-ofoccurrence points or more for each targeted pattern on a posttest of phonological skills? A secondary focus of this study was to determine if targeting specific sounds affected by a phonological pattern would result in generalization to targeted and non-targeted words.

\section{Definition of Terms}

The following terms are used for this investigation with definitions taken from Hodson and Paden (1991).

\section{General Terminology}

Homonymy. Producing the same phonetic form for two or more adult words that normally are not pronounced the same.

Maximal pairs. Two words that differ by more than one sound feature (e.g., pam and pack). 
Minimal pairs. Two words that differ by only one sound feature (e.g., tea and key).

\section{Basic Phonological Pattern Deviations Analyzed by the APP-R}

Consonant sequence omission. Omission of one or more sound segments from two or more contiguous consonants in the same syllable (e.g., snake $\rightarrow /$ nek/).

Glide deviation. A glide is omitted or substituted by a nonglide phoneme (e.g., yellow $\rightarrow /$ lelo/). Glide phonemes are $/ \mathrm{j} /$ and $/ \mathrm{w} /$.

Liquid // deviation. An $/ /$ phoneme is omitted or substituted by another phoneme (e.g., leaf $\rightarrow$ /wif/).

Liquid $/ \mathrm{r} /$ deviation. An $/ \mathrm{r} /$ phoneme is omitted or substituted by another phoneme (e.g., row $\rightarrow$ /wo/).

Nasal deviation. A nasal phoneme is omitted or substituted by a nonnasal phoneme (e.g., no $\rightarrow /$ do/). Nasal phonemes are $/ \mathrm{m} /, / \mathrm{n} /$, and $/ \eta /$.

Postvocalic singleton omission. Omission of a single consonant that terminates a word or syllable (e.g., boat $\rightarrow /$ bo/) .

Prevocalic singleton omission. Omission of single consonants that initiate words (e.g., boat $\rightarrow$ /ot/).

Strident deviation. A strident phoneme is omitted or substituted by a nonstrident phoneme (e.g., soap $\rightarrow$ /top/). Strident phonemes are $/ f, v, s, z, \int, \mathbf{z}$ t, $\mathrm{d} z /$

Syllable reduction. The number of syllables in the production of a word or utterance are reduced (e.g., banana $\rightarrow$ /naenə/).

Velar deviation. A velar phoneme is omitted or substituted by a nonvelar phoneme (e.g., key $\rightarrow / \mathrm{ti} /$ ). Velar phonemes are $/ \mathrm{k} /, / \mathrm{g} /$ and $/ \eta /$.

Other Phonological Pattern Deviation Terminology

Cluster reduction. Omission of one or more sound segments from two or more contiguous consonants in the same syllable (e.g., snake $\rightarrow /$ nek/). 
Final consonant deletion. Omission of a single consonant that terminates a word or syllable (e.g., boat $\rightarrow /$ bo/)

Prevocalic voicing. Addition of voicing to voiceless prevocalic consonants (e.g., two $\rightarrow / d u /)$.

Stopping. Substitution of a stop consonant for a fricative, liquid, nasal, or glide (e.g., sun $\rightarrow / t \Lambda n /)$.

Velar fronting. Replacing a velar phoneme $(/ \mathrm{k} /$ or $/ \mathrm{g} /)$ with an anterior phoneme (e.g., key $\rightarrow / \mathrm{ti} /$ ). 


\section{CHAPTER II}

\section{REVIEW OF THE LITERATURE}

Children who exhibit multiple articulation errors that render their speech unintelligible are thought to have underlying linguistic deficits. Just as a child with a language disorder may have difficulty acquiring the syntactic rules of a language, so a child may have difficulty acquiring the phonological rules of a language (Creaghead, 1989). Phonological-based treatment approaches are based on linguistic theory with the underlying assumption that children need to acquire the phonological rules of a language, rather than learning how to produce individual sounds.

Traditionally, articulation treatment methods have focused on the remediation of one or two phonemes at a time, usually beginning with early developing phonemes and progressing to later developing phonemes as each are mastered. However, when dealing with children who exhibit multiple articulation errors, traditional approaches may not be time efficient in terms of the remedial process. Furthermore, if these sound production problems are linguistically based, teaching children to produce isolated phonemes may not be beneficial in helping them learn appropriate phonological rules (Creaghead, 1989). Phonological-based treatment approaches are designed to help children learn the phonological system of their linguistic community.

Treatment based on linguistic theory assumes that speech-sound errors are the result of inadequate learning of phonological rules. It is presumed that children with multiple articulation errors are using inappropriate or early-developing phonological deviations such as velar fronting or final consonant deletion. The focus of treatment, therefore, is to eliminate these patterns and help children discover the phonological rules that will allow them to match the adult system (Weiss et al., 1987). 
Another assumption of phonological-based treatment approaches is that treatment of one or a few phonological patterns will result in the correction of several phonemes at once (Weiss et al., 1987). For example, elimination of the deviant phonological pattern of cluster reduction may affect all consonant clusters. The theory is that targeting deficient phonological patterns rather than individual phonemes as is seen in the more traditional approaches, allows for greater efficiency in the intervention process. In addition, it is proposed that for children whose problems are phonemic rather than phonetic, intervention should begin at the word level (Creaghead, 1989). Two types of phonological-based treatment approaches have emerged to treat children who are unintelligible: (a) the phonological cycling approach, and (b) the contrasting pairs approach.

\section{Concepts and Procedures}

Phonological Cycling Approach

Hodson and Paden (1991) devised a treatment program for children who are unintelligible. This program is based on the premise that phonological acquisition is a gradual process, and that listening is the primary mode by which children with normal hearing learn the adult sound system. Another underlying concept of this approach is that children associate kinesthetic with auditory sensations as they acquire new speech patterns. This ability allows for later self-monitoring. Hodson and Paden (1991) also assert that correct sound production is facilitated by certain phonetic environments, and that children tend to generalize these new speech production skills to other targets.

Based on these concepts, Hodson and Paden (1991) developed a program in which cycles focusing on phonological patterns are used to facilitate the development of intelligible speech patterns. This approach more closely approximates the way in which normal phonological development occurs. Cycles are time periods during which all phonological patterns that need remediation are facilitated in succession. Phonemes within 
targeted patterns are worked on in intervention sessions for 60 minutes to facilitate the emergence of new patterns. For example, one voiceless final stop consonant (e.g., $/ \mathrm{p} /)$ might be selected for intervention (60 to 90 minutes of remediation time) if the target phonological pattern of postvocalic singletons was selected for the first week of cycle one. Another voiceless final stop consonant (e.g., $/ \mathrm{t} /$ or $/ \mathrm{k} /$ ) would be targeted the following 60 to 90 minutes of remediation. These 2 target sounds might complete the focus on that target phonological pattern for cycle one and a new phonological pattern (e.g., /s/ clusters) would then be targeted for the following week of intervention. Phonological patterns are recycled during later cycles or time periods until each of the targeted phonological patterns emerge in spontaneous speech (Hodson \& Paden, 1991). Complexity of speech production is increased gradually during succeeding cycles by incorporating more difficult phonetic environments into production-practice words, by grouping phonemes within target patterns, and by incorporating minimal contrasting pairs (Hodson, 1989).

The length of each cycle varies from 5 to 16 weeks, depending on the number of deficient patterns, length of clinical sessions, and number of sessions per week. A phonological foundation is laid during the first cycle. During this cycle, children are allowed to experience early success on target patterns in carefully selected productionpractice words. Carryover to other words and to other situations is not expected until later cycles. Three to six cycles, involving approximately 40 to 60 minutes per week, of phonological remediation are usually required for a child who is phonologically disordered to become intelligible (Hodson, 1989).

\section{Efficacy}

The effectiveness of Hodson and Paden's (1991) phonological cycling approach was evaluated by Montgomery and Bonderman (1989) with a group of 9 unintelligible preschool-aged children. After two cycles of group intervention, all subjects showed 
improvement, receiving lower severity ratings on the final assessment as compared to the initial assessment. Final assessment also revealed that 2 children whose initial phonological deviancy scores placed them in profound severity intervals, received ratings of moderate to severe. Seven of the 9 subjects who received severe ratings on the initial assessment progressed to moderate or mild severity ratings by the end of the second cycle. Furthermore, 4 of the 9 subjects were dismissed after these two cycles (1989). Montgomery and Bonderman (1989) found this approach to be highly efficient. They attributed the success of this program to the targeting of phonological patterns, the group interactions, and the home program.

Tyler et al. (1987) implemented two phonological-based treatment procedures in an ongoing clinical program. Two subjects received intervention with a modified cycling approach and 2 received intervention with a minimal pairs approach. They adopted Hodson and Paden's (1991) procedures for perception and production training, but modified the format for scheduling phonological patterns for intervention. A cycle was defined as 3 weeks in length, and each week was the focus of one phonological pattern. Each week consisted of two 60-minute intervention sessions during which two targeted sounds were chosen to facilitate elimination of each pattern. Rather than having the children produce the target pattern with $100 \%$ accuracy as outlined by Hodson and Paden (1991), a different target sound was automatically the focus of the next session unless the child achieved only $20 \%$ or less accuracy. Each subject received two cycles of intervention.

Results of this study indicated that both the modified cycling approach and the minimal pairs approach were effective and efficient in eliminating or decreasing the occurrence of the phonological patterns selected for intervention. In addition, all 4 subjects displayed generalization to non-targeted sounds affected by the target phonological patterns (Tyler et al., 1987). These results support the hypothesis that 
phonological acquisition is a gradual process, as well as the assumption that articulation intervention is enhanced by treating deficient phonological patterns.

\section{Concepts and Procedures}

Contrasting Pairs Approach

Another commonly recommended form of a phonological-based treatment approach is the contrasting pairs approach, specifically the minimal pairs approach. Meaningful word contrasts are used to represent the difference in meaning when a specific phonological pattern is used and when it is not used (Weiss et al., 1987). The focus of this treatment approach is on the contrastive use of sounds and how they combine in word structures. This technique involves contrasting a pair of words in which one word contains the child's deficient phonological pattern and the other contains the target production.

A minimal pair consists of two words in which all segments are the same except one, and the two segments that do differ, do so by only one sound feature (Fokes, 1982). These minimal pair words become homophones when a child's speech-sound errors are produced. For example, bow and boat would be considered a minimal pair for a child who uses the phonologic pattern of final consonant deletion, or came and tame for the phonological pattern of velar fronting. These examples demonstrate how only one phonological pattern can change the meaning of the word. The minimal pairs approach is used to confront children with the semantic confusion created by their lack of phonemic contrast. It stresses the importance of making words different and teaches the linguistic function of phonological patterns (Blache \& Parsons, 1980).

Elbert and Gierut (1986) recommended using minimal pairs that represent maximal opposition as another method. Maximal pairs are used in words that differ by more than one sound feature in order to demonstrate the full range of sound possibilities to the child. 
For example, if a child is using the phonological pattern of final consonant deletion, the phoneme $/ \mathrm{m} /$ in the final position might be contrasted with $/ \mathrm{k} /$ (e.g., pam and pack).

A minimal pairs approach can be delivered in a number of ways in intervention. Blache (1982) described four steps that can be used to teach sounds or sound sequences for targeted phonological patterns. First, the child must understand that the two contrasting words differ in meaning. Second, receptive testing and training determine if the child perceives the phonological pattern separating the two words. Third, the child must produce the words in response to pictures or objects. A variety of game-like activities are then used for production training (Blache, 1982). For example, a child might request one of the two pictures illustrating the word pairs. A communication breakdown will result if the child does not produce the target sounds in the word pairs. It is presumed, therefore, that the child will make an effort to change or add the target sounds in order to clarify the semantic confusion (Fokes, 1982). Finally, Blache (1982) recommended that words be incorporated into communication situations outside the intervention session in order to maximize generalization.

\section{Efficacy}

Several studies of contrasting pairs approaches have been conducted in order to research the effectiveness and efficiency of eliminating or at least significantly reducing deficient phonological patterns.

Minimal pairs. The minimal pairs approach has been found to be an effective intervention procedure as evidenced by results reported by Weiner (1981). By teaching meaningful minimal pairs, Weiner showed a reduction in the frequency of final consonant deletion, stopping, and velar fronting in the phonological systems of 2 children with unintelligible speech. The basic strategy of his study was to confront the subjects with the fact that their speech-sound errors were resulting in miscommunications. Probes were administered to assess generalization of target phonological patterns to non-targeted 
words. Results of these generalization probes indicated that correct production of target phonological patterns generalized to non-targeted words following treatment with the minimal pairs approach. In addition to being an effective treatment technique, results suggest that this approach was also efficient. The phonological patterns exhibited in the 2 subjects decreased dramatically in a relatively short period of time (6 sessions for Subject A and 14 sessions for Subject B).

Saben and Ingham (1991) conducted a similar study using the minimal pairs approach, but found that their subjects failed to generalize targeted phonemes to nontargeted phonemes and words affected by the target phonological pattern. Two children with phonological disorders were administered a treatment program that utilized minimal pair words. Subject A was seen for 67 treatment sessions and was treated for the phonological pattern of stopping of fricatives in the final position. Subject B was seen for 32 treatment sessions and was treated for the phonological pattern of final consonant deletion of fricatives. Both subjects successfully progressed through the treatment program when it was augmented by imitation training and phonetic cues, but failed to generalize to non-targeted words.

Saben and Ingham (1991) provided several possible explanations as to why these 2 subjects failed to generalize. One possible reason might have been the way in which the minimal pairs were used in treatment. Rather than creating a natural communication breakdown which results from the homonymy of minimal pairs, subjects in this study were made aware that they were producing homophones. Past studies (Tyler et al., 1987; Weiner, 1981) have suggested that minimal pair treatment is successful because the child is motivated to make changes in the production of the target words in order to resolve the communication problem. The rationale underlying the minimal pairs approach is that children will actively avoid homonymy by changing their speech-sound productions. Saben and Ingham (1991), however, question the validity of this rationale and suggest 
that this assumption might be a second reason for the absence of generalization in their subjects. In light of the lack of research regarding the effectiveness of the minimal pairs approach, Saben and Ingham (1991) concluded that continued research in treating children with severe phonological disorders is needed.

Tyler, Figurski, and Langsdale (1993) conducted a study of 7 children with phonological disorders ( 4 with prevocalic voicing deficiencies and 3 with velar fronting). Subjects received two 45-minute treatment sessions with a minimal pairs procedure (Tyler et al., 1987), and acoustic measures were taken as subjects produced minimal pairs containing target and error speech sounds. Productive knowledge of the sound contrasts was assumed when acoustic distinctions were made. A shorter treatment period was seen for those subjects who exhibited productive knowledge of the contrast being trained, as compared to those who had no knowledge. One of the 4 prevocalic voicing subjects exhibited a significant acoustic distinction of the contrast being taught and required a shorter treatment period in comparison to the 3 subjects who did not display this same distinction. The 2 velar fronting subjects who exhibited productive knowledge of velars also required shorter treatment periods in comparison to the subject with no such knowledge. These results lend support to the findings of Tyler, Edwards, and Saxman (1990) who also found that a shorter treatment period was necessary for subjects who exhibited productive knowledge.

Maximal pairs. Gierut conducted a study in 1990 to evaluate whether minimal pairs (i.e., two words that differ by one sound feature) versus maximal pairs (i.e., two words that differ by more than one sound feature) would result in empirical differences in phonological acquisition. Three male subjects, aged 4, participated in the study. Each received intervention with both minimal and maximal pairs for two independent sound pairs. Both treatment plans and sound pairs were taught within each session. 
Results indicated that maximal pairs treatment led to greater improvement of targeted sounds than did minimal pairs treatment. Maximal pairs also provided for additions of non-targeted sounds to the posttreatment sound inventory of each subject. In addition, subjects displayed fewer changes in known sounds under the maximal pairs approach. Although both contrasting pair types of treatment effected change in the subject's phonological system, maximal pairs treatment provided a greater impact and allowed for more extensive sound learning than did treatment involving minimal pairs (Gierut, 1990).

\section{Summary}

The goal of phonological-based treatment approaches is to facilitate the development of phonological patterns used by adults in the child's linguistic community, rather than to remediate one or two phonemes at a time. These approaches are designed to intervene with children who exhibit multiple articulation errors that render their speech unintelligible. Finding an effective and efficient intervention technique that will result in improved intelligibility is crucial. However, research regarding efficacy and efficiency is lacking. It is imperative that the efficacy of phonological-based treatment approaches be evaluated on a regular basis and that every possible effort be made to provide these services in the least amount of time. This study was designed to evaluate the effectiveness of two phonological-based treatment approaches (i.e., the phonological cycling approach and the minimal pairs approach) in the remediation of a preschool child with unintelligible speech. Although empirical clinical studies of such procedures are still needed, a descriptive approach was chosen due to the nature of this study. 


\section{CHAPTER III}

\section{METHODS}

A descriptive, single-subject study detailing the course of phonological change during two phonological-based treatment approaches was conducted. One preschool child with unintelligible speech, characterized by deficient phonological patterns, was administered two treatment programs: the phonological cycling approach (Hodson and Paden, 1991) and the minimal pairs approach (Tyler et al., 1987). Individual sounds or sound sequences for targeted phonological patterns were taught, and production of targeted speech sounds for the target phonological patterns was measured periodically in targeted and non-targeted words.

Subject

A preschool male subject was selected from current applications received by the Portland State University Speech and Hearing Clinic. The subject exhibited a severe phonological disorder of unknown origin, characterized by numerous misarticulations that significantly reduced speech intelligibility. Criteria for inclusion in this investigation were as follows:

1. Written permission from the child's parent or guardian allowing the child's participation in the study (Appendix A).

2. Between the ages of 48 and 60 months.

3. Scoring within normal limits on The Peabody Picture Vocabulary Test-Revised (PPVT-R) (Dunn \& Dunn, 1981).

4. Passing a bilateral hearing screening at $20 \mathrm{~dB} \mathrm{HL}$ for the frequencies of 500 , 1000,2000 , and $4000 \mathrm{~Hz}$.

5. Standard English as the primary language spoken in the home.

6. Absence of a known developmental disability or physical deviancy. 
7. Severe or profound phonological disorder as measured by the Assessment of Phonological Processes-Revised (APP-R) (Hodson, 1986).

8. No prior articulation or phonological treatment.

9. Unintelligible rating of severe as measured by a 100 -word speech sample assessment using a dot-slash technique.

The subject of this study was a 4 year, 6 month old male ( 4 years, 8 months at the end of intervention) fitting the diagnostic classification of severe phonological disorder of unknown origin. The PPVT-R was administered to assess receptive language ability. This subject received a raw score of 61 , a standard score equivalent of 111 , and a stanine score of 7. This places the subject in the 77 th percentile. In addition, a bilateral hearing screening was administered and the subject passed at $20 \mathrm{~dB}$ HL for the frequencies of 500 , 1000,2000 , and $4000 \mathrm{~Hz}$. Table 1 displays APP-R results of percentage-of-occurrence scores for phonological pattern deviations as analyzed by the Computer Analysis of Phonological Deviation (CAPD) (Hodson, 1992a). In addition, this subject received an average phonological processes score of 53 and a phonological deviancy score of 58 . The severity interval was determined to be severe.

Speech intelligibility was measured by a 100 -word speech sample assessment using a dot-slash technique, with a dot indicating an intelligible word and a slash indicating an unintelligible word. An intelligibility percentage was determined by subtracting the total number of unintelligible words from the total 100 words. Based on a 100-word speech sample, this subject's speech intelligibly percentage was determined to be $35 \%$ at the beginning of the study, which translates to a severe rating.

\section{Experimental Design}

\section{Procedures}

A multiple-baseline design across behaviors with alternating treatment techniques was used in this single-subject study. Baseline measurements were taken at the beginning 
of each remediation program (every 2 weeks) and when a new phonological pattern was introduced as a target to determine the frequency of occurrence for each phonological pattern before treatment was initiated (see Appendix $\mathrm{C}$ for baseline/probe schedule). This was accomplished by eliciting responses to three targeted and three non-targeted words containing the target phonological patterns. Baseline measurements were taken to ensure experimental control and to determine effectiveness of treatment. A fifth phonological pattern was measured to serve as a control in this study.

Table 1

APP-R Percentage-of-Occurrence Summary (Pretest)

\begin{tabular}{c|c}
\hline Pattern Deviations & Percentage-of-Occurrence \\
\hline Syllable Reduction & 5 \\
\hline Prevocalic Singletons & 5 \\
\hline Postvocalic singletons & 16 \\
\hline Consonant Sequences & 90 \\
\hline Stridents & 58 \\
\hline Velars & 100 \\
\hline Liquid $/ /$ & 100 \\
\hline Liquid $/ \mathrm{r} /$ & 90 \\
\hline Nasals & 16 \\
\hline Glides & 50 \\
\hline
\end{tabular}

To measure generalization to targeted and non-targeted words after treatment was initiated, a probe list was constructed for the subject. This probe list (the same as the baseline list) contained five words for each phoneme in every syllable position of interest. 
Three words were randomly chosen and imitated by the subject for generalization measurement (see Appendix B for baseline/probe word list). During treatment, the probes followed the same schedule as the baseline measurement (see Appendix $\mathrm{C}$ for baseline/probe schedule).

\section{Pre- and Post-Test Measures}

Results of the APP-R were used to identify the phonological patterns that characterized the subject's phonological system, to determine progress, and to select target patterns for intervention. Presentation of 50 objects representing stimulus words provided the opportunity for use of the 10 basic phonological patterns analyzed by this instrument.

The test was administered according to manual specifications at the beginning of each remediation program (every 2 weeks), and again at the end of the study (Appendix C). All utterances were transcribed phonetically and tape recorded for later interobserver agreement. A second speech-language pathologist listened to the audiotape and transcribed the results. When differences occurred, the audiotape was reviewed until both listeners came to an agreement (Compton, 1970).

Transcribed responses were entered into the CAPD. An average percentage-ofoccurrence score for each of the 10 basic deviations, a phonological processes average, a phonological deviation average, and a severity interval were derived from the computer program, as well as the patterns recommended to be targeted.

\section{Target Selection}

Two phonological patterns were assigned by this investigator to be treated with the phonological cycling approach, and two were assigned to be treated with the minimal pairs approach. Based on results of the APP-R, as analyzed by the CAPD, the following phonological patterns were recommended as targets for intervention: consonant sequences / stridents, velars, liquid $/ /$, and liquid $/ \mathrm{r} /$. 
In an attempt to balance both phonological-based treatment approaches, the following phonological pattern assignments were made. Consonant sequences and stridents were targeted simultaneously based on the recommendations of Hodson and Paden (1991). Because consonant sequences / stridents and velars are earlier developing phonological patterns, they were assigned to different treatment approaches. The phonological pattern of consonant sequences / stridents was assigned to the phonological cycling approach and the phonological pattern of velars was assigned to the minimal pairs approach. Along similar lines of reasoning, liquids are later developing phonological patterns and therefore were assigned to different treatment approaches. Liquid $/ \mathrm{r} /$ was assigned to the phonological cycling approach and liquid $/ /$ was assigned to the minimal pairs approach. Glides $(/ \mathrm{w} /$ and $/ \mathrm{j} /)$ were not targeted for intervention, but were selected to be measured as a control phonological pattern. Even though the analysis of the CAPD did not select glides $(/ \mathrm{w} /$ and $/ \mathrm{j} /)$ as a potential target, it was chosen as a control phonological pattern because it had the next highest percentage-of-occurrence score at $50 \%$.

\section{Treatment Procedures}

Two treatment procedures were used in this single-subject study which included the phonological cycling approach and the minimal pairs approach (see Figure 1). Four phonological patterns (i.e., consonant sequences / stridents, velars, liquid $/ /$, and liquid $/ \mathrm{r} /$ ) were chosen as targets based on the results of the APP-R, as analyzed by the CAPD. Once the target patterns were chosen, intervention began.

The subject participated in 60-minute intervention sessions three times a week. Each phonological pattern was targeted for 6 hours of intervention. The first 2 weeks of treatment began with the phonological cycling approach and targeted the first two phonological patterns (i.e., consonant sequences / stridents and liquid $/ \mathrm{r} /$ ) for one cycle. A cycle was defined as 2 weeks for the purposes of this study, with one pattern being the 
focus for each week. Three training sounds were chosen to facilitate emergence of each target pattern; therefore, each sound was the focus of one intervention session in a given week. The minimal pairs approach was used to treat the third targeted pattern (i.e., velars) during weeks 3 and 4 . The phonological cycling approach was then employed again to treat the first two targeted patterns (i.e., consonant sequences / stridents and liquid $/ \mathrm{r} /$ ) for the second cycle during weeks 5 and 6 . And finally, the fourth targeted pattern (i.e., liquid $/ /$ ) was treated with the minimal pairs approach for weeks 7 and 8 . At the end of every 2 weeks, the APP-R was readministered to measure progress.

\begin{tabular}{|c|}
\hline $\begin{array}{l}\text { Phonological Cycling Approach - Weeks } 1 \& 2 \\
\text { Phonological Pattern } 1 \text { and } 2 \text { (Cycle } 1 \text { ) }\end{array}$ \\
\hline$\downarrow$ \\
\hline $\begin{array}{c}\text { Minimal Pairs Approach - Weeks } 3 \& 4 \\
\text { Phonological Pattern } 3\end{array}$ \\
\hline$\downarrow$ \\
\hline $\begin{array}{l}\text { Phonological Cycling Approach - Weeks } 5 \& 6 \\
\text { Phonological Patterns } 1 \text { and } 2 \text { (Cycle 2) }\end{array}$ \\
\hline$\downarrow$ \\
\hline $\begin{array}{l}\text { Minimal Pairs Approach - Weeks } 7 \& 8 \\
\text { Phonological Pattern } 4\end{array}$ \\
\hline
\end{tabular}

Figure 1. Flow chart of treatment procedures.

Phonological Processes Approach. Each session followed the guidelines outlined by Hodson and Paden (1991), and began with a brief review of the preceding session's words used for production-practice activities (see Figure 2). Next, the subject was introduced to the current session's target words by listening with a Realistic Stereo Amplified Listener (Model 33-1093) connected to a set of Realistic headphones to the clinician reading 12 to 15 words containing the session's target pattern. At the end of this auditory bombardment activity, the subject was asked to repeat three to five words into the amplifier's microphone from another list that was made up of potential production- 
practice words. Target words were carefully chosen for facilitative phonetic environments. Before any production-practice words were selected, they were first produced satisfactorily by the subject.

The subject then either drew, cut and pasted, or colored pictures of target words on 5- by 7 -inch index cards. These picture cards were incorporated into several different production-practice activities. Words were elicited using whatever cues were necessary for correct production, keeping in mind that only the target pattern needed to be correct. Before each session ended, a list of probe words was modeled to determine the next session's target words. At the end of the session, the auditory bombardment activity was repeated, again using slight amplification.

\begin{tabular}{|c|}
\hline Pattern 1 \\
(Consonant sequences / stridents) \\
$\downarrow$ \\
\hline Target Sound 1 - Initial /sp/ \\
$\downarrow$ \\
\hline Target Sound 2 - Initial /st/ \\
$\downarrow$ \\
\hline Target Sound 3 - Initial /sm/ \\
$\downarrow$ \\
\hline Pattern 2 \\
(Liquid /r/) \\
$\downarrow$ \\
\hline Target Sound 1 - Initial /r/ \\
$\downarrow$ \\
\hline Target Sound 2 - Final / r/ \\
$\downarrow$ \\
\hline Target Sound 3 - Medial /r/ \\
$\downarrow$ \\
\hline Post-Test / APP-R
\end{tabular}

Figure 2. Flow chart of phonological cycling approach (Tyler et al., 1987). 
A home program was also included in the intervention program. A parent was asked to read the listening list from the last session to the subject, followed by the subject reviewing the production-practice words once a day by naming the picture cards for the week. This activity usually took no more than 2 minutes a day.

Minimal Pairs Approach. The minimal pairs approach consisted of four levels of training including a perception level focusing on sound identification, and three production levels: word imitation, independent naming, and minimal pairs (see Figure 3). The subject first identified the target sound in isolation and then in single words. For example, the subject was required to identify the picture corresponding to the word containing the target pattern when presented with minimal pair pictures (such as sew and toe) with $90 \%$ accuracy in two consecutive trials.

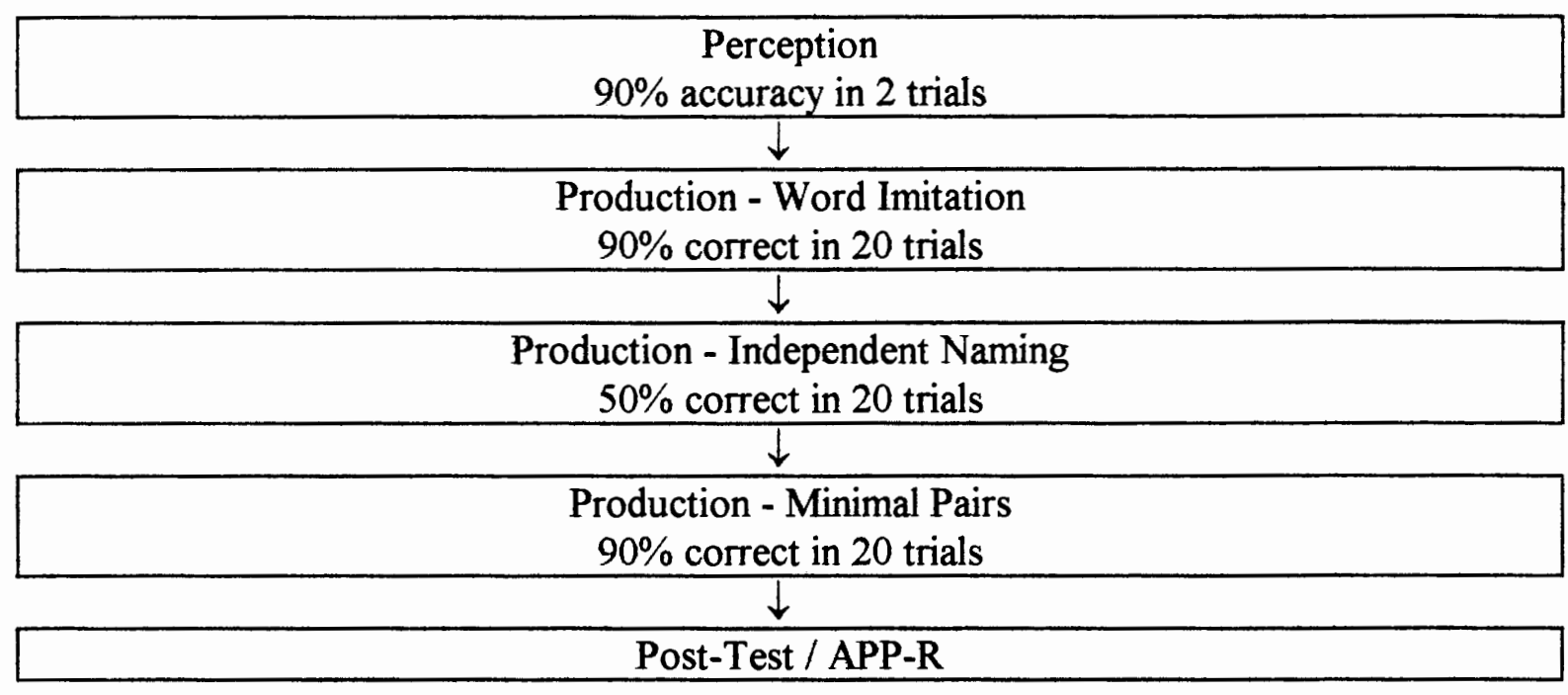

Figure 3. Flow chart of minimal pairs approach (Tyler et al., 1987).

After completing the perception level, the subject progressed to the production level. During the first level, word imitation, the subject produced the target sound in 5 to 10 carefully selected stimulus words prompted by the clinician's model. At this step, a home program was added where the subject reviewed the stimulus words once a day with 
a parent model. This parent model was removed once the subject reached the independent naming level. During the second production level, independent naming, the subject produced the target sound in the same set of stimulus words, but without the adult model. Criteria for advancing from word imitation to independent naming was $90 \%$ correct imitation of the target sound in 20 trials. After achieving $50 \%$ correct production of a target sound in 20 trials at the independent naming level, the subject advanced to the minimal pairs level. At this level, the subject was required to produce independently the target sound in five words during a variety of activities designed to take advantage of the semantic confusion created by an error production. After achieving $90 \%$ correct production in 20 trials, the subject then advanced to the next target sound, beginning at the perception level of training.

Correct responses were considered to be those that resulted in the elimination of the phonological pattern rather than in correct production of the target word. For example, in the case of velar fronting, production of any velar sound was regarded as correct and appropriately reinforced. After two consecutive errors, the clinician stopped the activity and offered the subject instruction.

\section{Data Measurement and Analysis}

This study was designed to investigate the effectiveness of two phonological-based treatment approaches as determined by a decrease of 10 percentage-of-occurrence points or more for each targeted pattern on a posttest of phonological skills. Results from the multiple baseline measures were used to demonstrate experimental control and effectiveness of treatment. Results of weekly probes were used to determine generalization of targeted phonological patterns to targeted and non-targeted words over time. 
Descriptive statistics were used to organize and summarize data. The data were displayed on tables and graphs, illustrating course of treatment through baseline measures and probes. 


\section{CHAPTER IV}

\section{RESULTS AND DISCUSSION}

\section{Results}

The research question posed was: Is there is significant difference between the phonological cycling approach (Hodson \& Paden, 1991) and the minimal pairs approach (Tyler et al., 1987) as determined by a decrease of 10 percentage-of-occurrence points or more for each targeted pattern on a posttest of phonological skills? In addition, probes were administered periodically to measure generalization of target phonological patterns to targeted and non-targeted words.

\section{Pre- and Post-Test Measures}

The subject of this investigation received 24 hours of intervention over an 8-week period, including 12 hours of intervention with the phonological cycling approach and 12 hours with the minimal pairs approach. The APP-R was administered as a pretest, at the beginning of each remediation program (every 2 weeks), and again at the conclusion of the study (Appendix C). Table 2 displays the phonological analysis summary of the APP-R, as analyzed by the CAPD. An average percentage-of-occurrence score for each of the 10 basic deviations, a phonological processes average, a phonological deviation average, and a severity interval were derived from the computer program and compared with previous APP-R scores.

Results of the CAPD indicate that percentage-of-occurrence scores for pattern deviations did not decrease by 10 points or more for any of this subject's targeted phonological patterns (i.e., consonant sequences/stridents, velars, liquid $/ /$, and liquid $/ \mathrm{r} /$ ). The scores for the patterns targeted through the minimal pairs approach (i.e., velars and liquid /) did not change nor did the scores for liquid $/ \mathrm{r} /$, which was the focus of the phonological cycling approach. The phonological patterns of consonant sequences / stridents increased by $3 \%$ and $2 \%$ respectively. 
Table 2

Phonological Analysis Summary of the APP-R

\begin{tabular}{|c|c|c|c|c|c|}
\hline \multirow{2}{*}{$\begin{array}{l}\text { Pattern } \\
\text { Deviations }\end{array}$} & \multicolumn{5}{|c|}{ Percentage of Occurrence } \\
\hline & $\begin{array}{c}\text { Day } 1 \\
\text { Pre-Test }\end{array}$ & $\begin{array}{l}\text { Week 2 } \\
\text { Cycling }\end{array}$ & $\begin{array}{c}\text { Week } 4 \\
\text { Minimal } \\
\text { Pairs }\end{array}$ & $\begin{array}{l}\text { Week } 6 \\
\text { Cycling }\end{array}$ & $\begin{array}{c}\text { Week } 8 \\
\text { Minimal } \\
\text { Pairs/Post- } \\
\text { Test }\end{array}$ \\
\hline $\begin{array}{l}\text { Syllable } \\
\text { Reduction }\end{array}$ & 5 & 5 & $\overline{0}$ & 5 & 5 \\
\hline $\begin{array}{l}\text { Prevocalic } \\
\text { Singletons } \\
\end{array}$ & 5 & 7 & 5 & 7 & 7 \\
\hline $\begin{array}{l}\text { Postvocalic } \\
\text { Singletons }\end{array}$ & 16 & 23 & 23 & 16 & 13 \\
\hline $\begin{array}{l}\text { Consonant } \\
\text { Sequences }\end{array}$ & 90 & 88 & 88 & 85 & 93 \\
\hline Stridents & 58 & 58 & 63 & 58 & 60 \\
\hline Velars & 100 & 100 & 100 & 95 & 100 \\
\hline Liquid /// & 100 & 100 & 100 & 100 & 100 \\
\hline Liquid $/ r /$ & 90 & 90 & 90 & 90 & 90 \\
\hline Nasals & 16 & 5 & 5 & 5 & 5 \\
\hline Glides & 50 & 60 & 50 & 50 & 50 \\
\hline $\begin{array}{l}\text { Average of } \\
\text { Phonological } \\
\text { Processes }\end{array}$ & 53 & 54 & 52 & 51 & 52 \\
\hline $\begin{array}{l}\text { Phonological } \\
\text { Deviancy } \\
\text { Score } \\
\end{array}$ & 58 & 59 & 57 & 56 & 57 \\
\hline $\begin{array}{l}\text { Severity } \\
\text { Interval }\end{array}$ & Severe & Severe & Severe & Severe & Severe \\
\hline
\end{tabular}


Glides $(/ \mathrm{w} /$ and $/ \mathrm{j} /$ ), which served as a control phonological pattern in this study, increased by 10 percentage-of-occurrence points after the first 2 weeks of the phonological cycling approach, but then decreased 10 points after the first 2 weeks of the minimal pairs approach and remained at the pretest level (i.e., 50\%). Nasals, which were not targeted for intervention nor served as a control, did decrease by 11 percentage-ofoccurrence points after 2 weeks with the phonological cycling approach and remained stable. Postvocalic singletons, a non-targeted and non-control pattern, increased from a percentage-of-occurrence score of 16 to 23 after the first 2 weeks of the phonological cycling approach, where it remained for the following 2 weeks of the minimal pairs approach. This score then dropped back to 16 after the last 2 weeks of the phonological cycling approach, and finally to a posttest score of 13 .

Overall, percentage-of-occurrence scores varied widely between pretest and posttest scores, and during the course of treatment. These scores increased randomly by as much as 8 points and decreased by as much as 11 points. Pretest and posttest scores of the APP-R revealed that while the severity interval remained severe, both the phonological processes average and the phonological deviancy score decreased minimally. In addition, no significant differences in scores were noted between remediation programs.

\section{Phonological Cycling Approach}

The subject of this study received 4 weeks (two cycles) of intervention, 3 hours a week, with the phonological cycling approach. Two phonological patterns were chosen as targets for this approach based on results of the APP-R, as analyzed by the CAPD: (a) consonant sequences / stridents, and (b) liquid / $r$ /. Consonant sequences / stridents were the focus of the first three sessions of cycles one and two, and liquid /r/ was the focus of the last three sessions of cycles one and two. Table 3 displays the phonological patterns targeted for each cycle during the phonological cycling approach. Hodson and Paden 
(1991) emphasize correct production of the target phonological pattern with as many correct responses as can naturally be achieved in any given activity.

Table 3

Cycles and Training Targets for Phonological Cycling Approach

\begin{tabular}{|c|c|c|c|c|c|}
\hline Cycle & Week & Target Pattern & \multicolumn{3}{|c|}{$\begin{array}{c}\text { Target Sound Each } \\
\text { Session }\end{array}$} \\
\hline \multirow[t]{2}{*}{1} & 1 & $\begin{array}{l}\text { Consonant Sequences / } \\
\text { Stridents }\end{array}$ & $\begin{array}{l}\text { Initial } \\
/ \mathrm{sp} /\end{array}$ & $\begin{array}{l}\text { Initial } \\
\text { /st/ }\end{array}$ & $\begin{array}{l}\text { Initial } \\
/ \mathrm{sm} /\end{array}$ \\
\hline & 2 & Liquid /r/ & $\begin{array}{l}\text { Initial } \\
/ \mathrm{r} /\end{array}$ & $\begin{array}{l}\text { Final } \\
/ \mathrm{r} /\end{array}$ & $\begin{array}{l}\text { Medial } \\
/ \mathrm{r} /\end{array}$ \\
\hline \multirow[t]{2}{*}{2} & 5 & $\begin{array}{l}\text { Consonant Sequences / } \\
\text { Stridents }\end{array}$ & $\begin{array}{l}\text { Initial } \\
/ \mathrm{sp} /\end{array}$ & $\begin{array}{l}\text { Initial } \\
\text { /st/ }\end{array}$ & $\begin{array}{l}\text { Initial } \\
/ \mathrm{sm} /\end{array}$ \\
\hline & 6 & Liquid /r/ & $\begin{array}{l}\text { Initial } \\
/ \mathrm{r} /\end{array}$ & $\begin{array}{l}\text { Final } \\
/ \mathbf{r} /\end{array}$ & $\begin{array}{l}\text { Medial } \\
\mid \mathrm{r} /\end{array}$ \\
\hline
\end{tabular}

\section{Minimal Pairs Approach}

The subject of this investigation also received 4 weeks of intervention, 3 hours a week, with the minimal pairs approach. The phonological patterns of velars and liquid / $/$ were chosen as targets based on results of the APP-R, as analyzed by the CAPD. This subject received intervention on velars for 2 weeks (weeks 3 and 4 ) and liquid /1/ for 2 weeks (weeks 7 and 8).

Treatment of velars did not progress past initial $/ \mathrm{k} /$ as the subject failed to meet criteria at the fourth level of training. Results of treatment using the minimal pairs approach with velars are displayed in Table 4. The subject of this study advanced through all four levels of training for both initial $/ /$ and final $\Lambda$. Table 5 displays results of treatment using the minimal pairs approach with liquid $\Lambda$.

\section{Baseline and Probes}

Baseline measurements and generalization probes of the target phonological patterns were taken at the beginning of each remediation program (every 2 weeks) and 
when a new phonological pattern was introduced as a target. Daily probes were also taken of the phonological pattern targeted for each treatment session in order to measure generalization to imitated targeted and non-targeted words over time. The frequency of occurrence for each phonological pattern was determined by eliciting responses to three targeted and non-targeted words containing the target phonological patterns. Baseline and probe measures were also taken of a fifth phonological pattern (i.e., glides) that served as a control in this study.

Table 4

Results of Minimal Pairs Approach with Velars by Session

\begin{tabular}{|c|c|c|c|c|c|c|c|}
\hline \multirow[t]{3}{*}{ Steps } & \multirow{3}{*}{$\begin{array}{c}\text { Criterion } \\
\text { for } \\
\text { Movement }\end{array}$} & \multicolumn{6}{|c|}{ Progress for Each Session } \\
\hline & & \multicolumn{3}{|c|}{$\begin{array}{c}\text { Week } 3 \\
\text { Initial } / \mathbf{k}\end{array}$} & \multicolumn{3}{|c|}{$\begin{array}{c}\text { Week } 4 \\
\text { Initial } / \mathrm{k}\end{array}$} \\
\hline & & Day 1 & Day 2 & Day 3 & Day 1 & Day 2 & Day 3 \\
\hline Perception & $\begin{array}{c}90 \% \\
\text { accuracy } \\
\text { in } 2 \text { trials }\end{array}$ & $\begin{array}{l}9 / 10 \\
90 \%\end{array}$ & & & & & \\
\hline $\begin{array}{c}\text { Production - } \\
\text { Word } \\
\text { Imitation }\end{array}$ & $\begin{array}{c}90 \% \text { correct } \\
\text { in } 20 \text { trials } \\
(18 / 20)\end{array}$ & $\begin{array}{c}13 / 20 \\
65 \%\end{array}$ & $\begin{array}{c}10 / 20 \\
50 \%\end{array}$ & $\begin{array}{l}8 / 20 \\
40 \%\end{array}$ & $\begin{array}{l}20 / 20 \\
100 \%\end{array}$ & & \\
\hline $\begin{array}{l}\text { Production - } \\
\text { Independent } \\
\text { Naming }\end{array}$ & $\begin{array}{c}50 \% \text { correct } \\
\text { in } 20 \text { trials } \\
(10 / 20)\end{array}$ & & & & $\begin{array}{l}13 / 20 \\
65 \%\end{array}$ & & \\
\hline $\begin{array}{l}\text { Production - } \\
\text { Minimal } \\
\text { Pairs }\end{array}$ & $\begin{array}{c}90 \% \text { correct } \\
\text { in } 20 \text { trials } \\
(18 / 20)\end{array}$ & & & & & $\begin{array}{c}10 / 20 \\
50 \%\end{array}$ & $\begin{array}{c}11 / 20 \\
55 \%\end{array}$ \\
\hline
\end{tabular}


Table 5

Results of Minimal Pairs Approach with Liquid // by Session

\begin{tabular}{|c|c|c|c|c|c|c|c|}
\hline \multirow{3}{*}{ Steps } & \multirow{3}{*}{$\begin{array}{c}\begin{array}{c}\text { Criterion } \\
\text { for } \\
\text { Movement }\end{array} \\
\end{array}$} & \multicolumn{6}{|c|}{ Progress for Each Session } \\
\hline & & \multicolumn{3}{|c|}{$\begin{array}{c}\text { Week } 7 \\
\text { Initial /// }\end{array}$} & \multicolumn{3}{|c|}{$\begin{array}{l}\text { Week } 8 \\
\text { Final } / /\end{array}$} \\
\hline & & Day 1 & Day 2 & Day 3 & Day 1 & Day 2 & Day 3 \\
\hline Perception & $\begin{array}{c}90 \% \\
\text { accuracy } \\
\text { in } 2 \text { trials }\end{array}$ & $\begin{array}{l}9 / 10 \\
90 \%\end{array}$ & & & $100 \%$ & & \\
\hline $\begin{array}{l}\text { Production - } \\
\text { Word } \\
\text { Imitation }\end{array}$ & $\begin{array}{c}90 \% \text { correct } \\
\text { in } 20 \text { trials } \\
(18 / 20)\end{array}$ & $\begin{array}{l}18 / 20 \\
90 \%\end{array}$ & & & $\begin{array}{l}14 / 20 \\
70 \%\end{array}$ & $\begin{array}{l}18 / 20 \\
90 \%\end{array}$ & \\
\hline $\begin{array}{l}\text { Production - } \\
\text { Independent } \\
\text { Naming }\end{array}$ & $\begin{array}{c}50 \% \text { correct } \\
\text { in } 20 \text { trials } \\
(10 / 20) \\
\end{array}$ & $\begin{array}{c}12 / 20 \\
60 \%\end{array}$ & & & & $\begin{array}{c}15 / 20 \\
75 \%\end{array}$ & \\
\hline $\begin{array}{c}\text { Production - } \\
\text { Minimal } \\
\text { Pairs } \\
\end{array}$ & $\begin{array}{c}90 \% \text { correct } \\
\text { in } 20 \text { trials } \\
(18 / 20)\end{array}$ & & $\begin{array}{l}13 / 20 \\
65 \%\end{array}$ & $\begin{array}{l}18 / 20 \\
90 \%\end{array}$ & & & $\begin{array}{l}18 / 20 \\
90 \%\end{array}$ \\
\hline
\end{tabular}


Baseline. Figures 4 through 8 display results of baseline measures taken for each of the targeted phonological patterns. Results indicate that the baseline for frequency of occurrence for each of the phonological patterns targeted for treatment was stable prior to the initiation of treatment. Glides (i.e., /w/ and /j/), which were chosen as a fifth phonological pattern, served as a control in this study and also remained unchanged throughout the course of treatment.

Probes. Generalization of target phonological patterns to targeted and nontargeted words is also displayed in Figures 4 through 8 . The results of probing targeted and non-targeted words for the target phonological pattern of consonant sequences / stridents are displayed in Figure 4. The subject of this study generalized consonant sequences / stridents to targeted and non-targeted words with $100 \%$ accuracy after 2 days of intervention (cycle one) with the phonological cycling approach. Generalization to targeted words continued at $100 \%$ accuracy 1 day after finishing the phonological cycling approach, whereas non-targeted words decreased to $89 \%$. Both targeted and nontargeted words fell to $0 \%$ after 3 weeks without intervention. However, generalization to non-targeted words increased back to $100 \%$ accuracy, and targeted words increased to $67 \%$ accuracy after 1 day of treatment with cycle two of the phonological cycling approach. Generalization of consonant sequences / stridents to both targeted and nontargeted words decreased to $22 \%$ and $33 \%$ respectively, within 3 days without treatment for these patterns.

Figure 5 displays results of generalization probes for the target phonological pattern of liquid $/ \mathrm{r} /$. Results indicate that generalization to non-targeted words over time did not occur. Furthermore, generalization to targeted words occurred with $11 \%$ accuracy on the last day of cycle two of the phonological cycling approach.

Probe results for the target phonological pattern of velars are displayed in Figure 6. Generalization to targeted words occurred with $17 \%$ accuracy on the day after 
Baseline \& Generalization Probes

Phonological Cycling Approach



Figure 4. Percentage of correct production of consonant sequences / stridents ber session.

Baseline \& Generalization Probes Phonological Cycling Approach



Figure 5. Percentage of correct production of liquid $/ r /$ per session.

Baseline \& Generalization Probes Minimal Pairs Approach

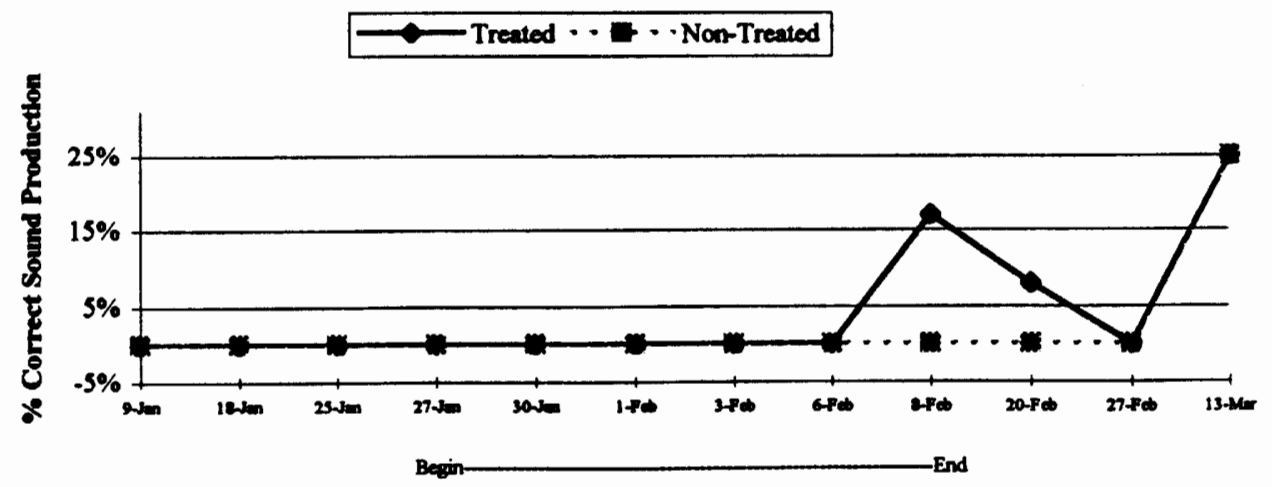

Figure 6. Percentage of correct production of velars per session. 


\section{Baseline \& Generalization Probes \\ Minimal Pairs Approach}

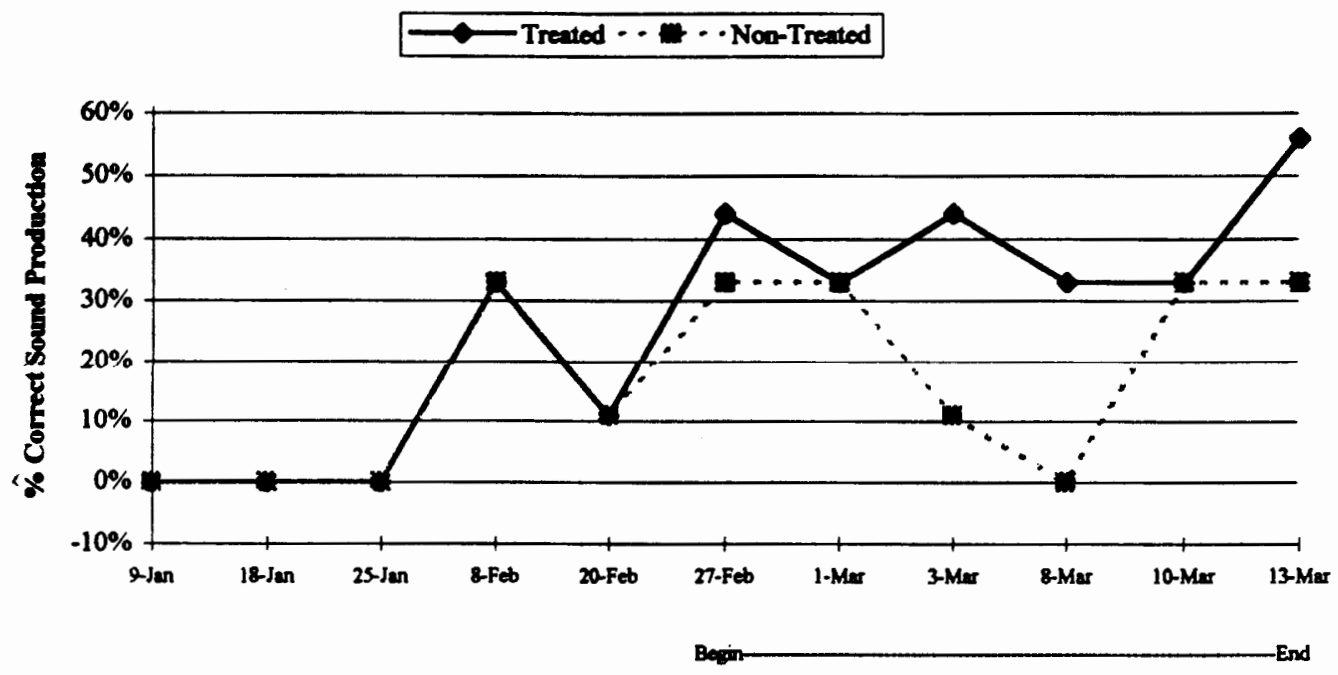

Figure 7. Percentage of correct production of liquid $N$ per session.

\section{Baseline \& Generalization Probes}



Figure 8. Percentage of correct production of glides $(/ \mathrm{w} /$ and $/ \mathrm{j} /)$ per session. 
finishing treatment with the minimal pairs approach. These results then decreased to $8 \%$ by the following probe measurement. Generalization to non-targeted words did not occur at all until the last session of the study when it increased to $25 \%$ accuracy.

Generalization of the phonological pattern of liquid $/ 1 /$ is displayed in Figure 7. Both targeted and non-targeted words were produced with $33 \%$ accuracy, six sessions before liquid $/ /$ was targeted with the minimal pairs approach. Production of both targeted and non-targeted words remained between $11 \%$ and $44 \%$ accuracy before treatment began. Results indicate that generalization to non-targeted words decreased to $0 \%$ by the fourth day of the minimal pairs approach, before increasing again to $33 \%$ accuracy by the last day of the study. Generalization to targeted words remained between $33 \%$ and $44 \%$ accuracy after treatment began, but increased to $56 \%$ accuracy by the last day.

Probe results of the phonological pattern of glides are displayed in Figure 8. Generalization to non-targeted words did not occur.

Discussion

Improvement resulting from two phonological-based treatment programs was closely monitored through APP-R scores and generalization probes. Both intervention programs resulted in minimal changes in the phonological system, and consequently, in the number of speech sounds errors exhibited by the subject of this study. These results do not support those of Tyler et al., (1987) whose research with both a modified cycling approach and a minimal pairs approach yielded positive results. All 4 subjects in their study demonstrated marked changes in their phonological systems as demonstrated by results of pretreatment and follow-up generalization probes.

Overall, the phonological patterns targeted for treatment displayed very little change over the 8-week intervention period as determined by pretest and posttest scores of the APP-R. Results of probe measurements indicated little if any generalization to 
targeted and non-targeted words for any of the targeted patterns, except for the target phonological pattern of consonant sequences / stridents after the phonological cycling approach. This may suggest that the phonological cycling approach was more effective for this subject than the minimal pairs approach.

\section{Pre-and Post-Test Measures}

Results of the CAPD indicated minimal changes between pretest and posttest scores for all of this subject's targeted phonological patterns. The reasons for the lack of change are unclear, although it is possible to speculate as to why improvements were not noted on the APP-R. One reason for the lack of change might be that not enough time was spent on each pattern. For the purposes of this study, a cycle was defined as 2 weeks in length. Hodson and Paden (1991), in fact, do not make this time restriction. They maintain that the length of a cycle depends on the number of patterns targeted, as well as the number of stimulable phonemes within each target pattern. In addition, Hodson and Paden (1991) point out that improvements should not be expected to occur until after cycle two, when a phonological foundation has been established.

A second possible explanation for the lack of change between pretest and posttest scores might lie in the experimental design of this study. It is possible that alternating between the phonological cycling approach and the minimal pairs approach was somehow confusing for this subject, therefore inhibiting the suppression of targeted phonological patterns.

\section{$\underline{\text { Probes }}$}

Phonological cycling approach. The phonological cycling approach facilitated marked changes in the frequency of the target phonological pattern of consonant sequences / stridents as measured in the imitated word probe task after two cycles (six sessions). Thus, the subject of this study displayed generalization of the target phonological pattern to targeted and non-targeted words. However, correct production of 
non-targeted words lagged behind that of targeted words. These results support those of Weiner (1981) by demonstrating that generalization occurs in non-targeted words affected by the phonological patterns targeted for intervention. Weiner also found that production of non-targeted words lagged behind that of the targeted words. However, in this study generalization of liquid $/ r /$ to both targeted and non-targeted words did not occur.

There are a number of possible explanations as to why this intervention approach worked so well with one phonological pattern and not the other. Hodson and Paden (1991) base their phonological approach and order of presentation on developmental and clinical phonology research findings. For example, developmental phonology research findings revealed that / $/$ / clusters emerge in utterances of typically developing children between the ages of 2 and 3 years. Consonant sequences / stridents, therefore, is one of the first phonological patterns Hodson and Paden (1991) recommend to be targeted for treatment. This pattern was the most stimulable pattern for this subject, perhaps suggesting a certain readiness to learn.

Liquid $/ r$ /, on the other hand, is a later developing sound. Hodson and Paden (1991) do recommend liquids as an appropriate priority pattern for beginning cycles; however, liquids are not expected to be produced perfectly during the first cycle. The goal is to suppress the gliding pattern. The words are usually broken apart and the stress is placed on the vowel. Only during later cycles is liquid $/ r /$ blended into the vowel. These recommendations were followed in this study as the subject was unable to suppress the gliding pattern without separating liquid $/ \mathrm{r} /$ from the vowel. This may be an explanation as to why liquid /r/did not generalize to targeted or non-targeted words. Furthermore, Hodson and Paden (1991) recommend that only initial and final $/ r /$ be the focus of intervention. Medial /r/ was mistakenly targeted during both cycles in this study, which may have further inhibited the generalization of this pattern. 
Minimal pairs approach. The minimal pairs approach did not facilitate generalization for the target phonological pattern of velars to targeted and non-targeted words. In addition, generalization of liquid $/ /$ to targeted and non-targeted words was minimal. In fact, this pattern started to emerge 3 days before it was targeted for intervention. Liquid / $\mathrm{r} /$ was the focus of intervention with the phonological cycling approach during the 3 days when this subject made some mild gains in generalization of liquid $/ V$. It is possible that the generalization of liquid $/ /$ was facilitated by the phonological cycling approach, even though it was not the focus of intervention.

In addition, this subject failed to meet all the various performance criteria required at each step of the minimal pairs approach. For example, the subject failed to meet criteria for the last step of the program (i.e., minimal pairs production) after 2 weeks of intervention for the phonological pattern of velars, specifically initial $/ \mathrm{k} /$. This could account for the lack of generalization to targeted and non-targeted words for this phonological pattern. Furthermore, it can be claimed that the minimal pairs approach was not only ineffective for this subject, but inefficient. These results do not support those of Weiner (1981), who reported dramatic changes in application of target patterns treated by a minimal pairs technique in 6 sessions for one subject and 14 sessions for another.

There are several possible explanations as to why this subject failed to generalize. One reason may lie in the design of the minimal pairs approach. Historically, the success of the minimal pairs approach has been attributed to the communication breakdown that occurs when homophones are produced as a result of the child's speech sounds errors. It is then assumed that the child will make a change in the production of the target word to resolve the communication problem. In this study, the communication breakdown was only induced during the last step of the program (i.e., minimal pairs production). During intervention for the phonological pattern of velars, the subject did not move to the last 
step until the fifth day of intervention. Thus this subject could not fully benefit from the communication breakdowns created by the minimal pair words.

Another possible reason for the absence of generalization to targeted and nontargeted words may be that the rationale underlying the minimal pairs approach is deficient. As stated above, this approach is based on the supposition that children will change their speech-sound production when confronted with the homonymy that results from their speech-sound errors. This rationale assumes that children will actively avoid homonymy. The subject of this study did avoid homonymy, but not by making speechsound changes. First the subject tried to avoid all the words which contained the deficient phonological pattern by choosing only those words which were easy to produce. This demonstrates that although the subject was aware of the homonymy created by the speech-sound errors, there was no attempt to change those errors, rather an attempt to avoid them entirely. Only when left with no other choices, did the subject make the appropriate speech sound changes.

Other considerations. The success seen with regard to the generalization of the phonological pattern of consonant sequences / stridents and to a lesser degree liquid $/ /$, can perhaps be attributed to the fact that intervention may have interacted with maturation so as to facilitate the normal acquisition process.

\section{Summary}

Overall, minimal changes were noted in the phonological system of this subject after receiving intervention with both the phonological cycling approach and the minimal pairs approach. However generalization probes for the target phonological pattern of consonant sequences / stridents revealed marked changes on an imitated word task as a result of the phonological cycling approach. 


\section{CHAPTER V}

\section{SUMMARY AND IMPLICATIONS}

Summary

This single-subject study was designed to compare the effectiveness of two phonological-based treatment approaches with a preschool male with unintelligible speech characterized by deficient phonological patterns. Four phonological patterns were chosen as targets based on results of the APP-R, as analyzed by the CAPD. The subject participated in 60-minute intervention sessions three times a week over an 8-week period. The phonological cycling approach (Hodson \& Paden, 1991) was the focus of 4 weeks of intervention, and the minimal pairs approach (Tyler et al., 1987) was the focus of 4 weeks of intervention. Remediation programs were alternated every 2 weeks, and began with the phonological cycling approach. Results were measured through pretests and posttests of the APP-R, as well as baseline and generalization probes that were administered periodically.

Results of the CAPD indicated minimal changes between pretest and posttest scores for all of this subject's targeted phonological patterns (i.e., consonant sequences / stridents, velars, liquid $/ \mathrm{V}$, and liquid $/ \mathrm{r} /$ ). In addition, no significant differences in scores were noted between remediation programs. Results of probe measurements indicated little, if any, generalization to targeted and non-targeted words in an imitated word probe task for any of the targeted patterns, except for the target phonological pattern of consonant sequences / stridents after the phonological cycling approach. This finding may suggest that the phonological cycling approach was more effective for this subject than the minimal pairs approach. 


\section{Clinical Implications}

\section{Implications}

Based on the results of this investigation, several issues can be considered regarding the selection of a phonological-based treatment approach. First of all, neither of these phonological-based treatment programs facilitated much change in the phonological system of this subject. The phonological cycling approach appeared to more effective for this subject than the minimal pairs approach in that generalization occurred during this intervention program to targeted and non-targeted words for the target phonological pattern of consonant sequences / stridents.

There are a number of variables that may make individual children better suited to one intervention procedure over another. For instance, learning style may be one variable to consider when choosing an intervention program, as well as the child's phonetic inventory, the number of deficient phonological patterns, and their frequency of occurrence. Age is an important consideration, especially with regard to the minimal pairs approach. Children must be old enough to recognize and produce, not only the phonetic distinction between minimal pair words, but the phonemic distinction as well. It seems plausible to suggest that the minimal pairs approach might be appropriate for phonological patterns for which a child has some degree of productive knowledge.

Tyler et al. (1987) suggested that children who exhibit a number of inappropriate phonological patterns that reduce intelligibility may be better candidates for the phonological cycling approach where several patterns are targeted at once. Good candidates for the minimal pairs approach may be those children who have only one or a few particularly pervasive patterns. This is because the minimal pairs approach concentrates on one phonological pattern at a time. For children with extensive speech errors, this kind of approach likely is more time consuming. There may be children who 
benefit from a combination of both intervention procedures. Most importantly, individual variations need to be considered before any intervention approach is chosen.

\section{Research Implications}

Based on the results of this investigation, several recommendations can be made for future research regarding the effectiveness of the phonological cycling approach and the minimal pairs approach. For example, it is suggested that a replicated study of this current investigation be conducted to confirm the validity of these results. In addition, it is recommended that future studies target phonological patterns for longer time periods (i.e., 16 weeks instead of 8 weeks), or until targeted phonological patterns reach the dismissal criteria as defined by each remediation approach. Future studies could also replicate the methods and procedures of this investigation, but reverse the phonological patterns targeted for each approach. For instance, the phonological patterns of consonant sequences / stridents and liquid / $\mathrm{r}$ / could be assigned to the minimal pairs approach, and the phonological patterns of velars and liquid $/ \mathrm{N}$ could be assigned to the phonological cycling approach. A multiple baseline design across subjects with similar phonological systems could also be used in a future research project. One subject could receive treatment with the phonological cycling approach and another subject could receive treatment with the minimal pairs approach. Furthermore, those who are routinely working in the field need to be alert for opportunities to develop and test new clinical hypotheses.

Well-controlled treatment studies are needed in order to develop more effective and efficient treatment techniques to reduce the potentially negative effects of unintelligible speech patterns. Carefully designed studies comparing phonological-based treatment procedures for children with unintelligible speech are needed. Most of the studies conducted to evaluate the effectiveness of the phonological cycling approach have implemented a modified approach (i.e., Tyler et al, 1987), rather than exactly as Hodson and Paden (1991) have outlined for individual intervention. Based on this, research 
designed specifically on Hodson and Paden's (1991) phonological cycling approach is needed in order to adequately determine the effectiveness of the program.

Similarly, limited empirical data have been reported in the literature regarding the efficacy of the minimal pairs approach. More research is needed to investigate the effectiveness of this approach with children who are highly unintelligible and whose speech can be characterized by deficient phonological patterns. Factors such as age and productive knowledge must be considered and assessed. Additional studies need to be carried out for both phonological-based treatment programs that consider such factors as number of contact hours, length of intervention programs, groups intervention designs, parent participation, carry over, and phonological targets that yield the greatest intelligibility gains.

Although generalization from single-subject data has limitations, the results of this study do make an important contribution to the small body of information available regarding the effectiveness of the various phonological-based treatment approaches. Nevertheless, a great deal more research is needed in the area of intervention efficacy and efficiency for children with phonological disorders. 


\section{References}

Blache, S. E. (1982). Minimal word pairs and distinctive feature training. In M. Crary (Ed.), Phonological intervention (pp. 61-96). San Diego: College-Hill Press, Inc.

Blache, S. E., \& Parsons, C. L. (1980). A linguistic approach to distinctive feature training. Language, Speech, and Hearing Services in Schools, 11, 203-207.

Compton, A. J. (1970). Generative studies of children's phonological disorders. Journal of Speech and Hearing Disorders, $\underline{35}, 315-339$.

Creaghead, N. A. (1989). Linguistic approaches to treatment. In N. A. Creaghead, P. W. Newman, \& W. A. Secord (Eds.), Assessment and remediation of articulatory and phonological disorders (pp. 193-209). Columbus, OH: Merrill Publishing Company.

Dunn, L., \& Dunn, L. (1981). Peabody picture vocabulary test-revised. Circle Pines, MN: American Guidance Service.

Elbert, M., \& Gierut, J. (1986). Handbook of clinical phonology: Approaches to assessment and treatment. San Diego: College-Hill Press, Inc.

Fokes, J. (1982). Problems confronting the theorist and practitioner in child phonology. In M. Crary (Ed.), Phonological intervention (pp. 13-34). San Diego: College-Hill Press, Inc.

Gierut, J. A. (1990). Differential learning of phonological oppositions. Journal of Speech and Hearing Research, 33, 540-549.

Hodson, B. W. (1986). Assessment of phonological processes-revised. Austin, TX: Pro Ed.

Hodson, B. W. (1989). Phonological remediation: A cycles approach. In N. A Creaghead, P. W. Newman, \& W. A. Secord (Eds.), Assessment and remediation of articulatory and phonological disorders (pp. 323-332). Columbus, $\mathrm{OH}$ : Merrill Publishing Company. 
Hodson, B. W. (1992a). Computer analysis of phonological deviations. Stonington, IL: Phono Comp Software.

Hodson, B. W. (1992b). Phonological assessment and treatment applied phonology: Constructs, contributions, and issues. Language, Speech, and Hearing Services in Schools, 23, 247-253.

Hodson, B. W., \& Paden, E. P. (1991). Targeting intelligible speech (2nd ed.). Austin, TX: Pro-Ed.

Montgomery, J. K., \& Bonderman, I. R. (1989). Serving preschool children with severe phonological disorders. Language, Speech and Hearing Services in Schools, $\underline{20}$, 76-84.

Saben, C. B., \& Ingham, J. C. (1991). The effects of minimal pairs treatment on the speech-sound production of two children with phonologic disorders. Journal of Speech and Hearing Research, 34, 1023-1040.

Tyler, A. A., Edwards, M. L., \& Saxman, J. H. (1987). Clinical application of two phonologically based treatment procedures. Journal of Speech and Hearing Disorders, 52, 393-409.

Tyler, A. A., Edwards, M. L., \& Saxman, J. H. (1990). Acoustic validation of phonological knowledge and its relationship to treatment. Journal of Speech and Hearing Disorders, 55, 251-261.

Tyler, A. A., Figurski, G. R., Langsdale, T. (1993). Relationships between knowledge of stop place and voicing contrasts and phonological treatment progress. Journal of Speech and Hearing Research, $\underline{36}, 746-759$.

Weiner, F. (1981). Treatment of phonological disability using the method of meaningful minimal contrasts: Two case studies. Journal of Speech and Hearing Disorders, $46,97-103$. 
Weiss, C., Gordon, M., \& Lillywhite, H. (1987). Clinical management of articulatory and phonologic disorders (2nd ed.). Baltimore: Williams and Wilkins. 


\section{APPENDIX A}

\section{Consent Form}

I, the parent of , hereby agree to allow my child to serve as a subject for

the investigation of: Clinical Application of Two Phonological Based Treatment Approaches. This study is conducted by Holly Kiesz Royer, under the supervision of Mary Gordon-Brannan, Associate Professor, Portland State University.

I understand that this study involves my child's participation in an intervention technique designed to improve his/her speech intelligibility.

I understand that there is no risk involved in this study. The only inconvenience involves my time of 3 hours of intervention per week, and 2 to 3 minutes of daily home practice with my child.

It has been explained to me that the purpose of this study is to learn if one type of approach, the phonological cycling approach, will improve the speech intelligibility of a preschool child better than another approach, the minimal pairs approach.

My child may not receive any direct benefit from participation in this study, but his/her participation may help to increase knowledge which may benefit others in the future.

Holly Kiesz Royer has offered to answer any questions I may have about the study and what is expected of me and my child in the study. I have been assured that all information I give will be kept confidential and that the identity of my child will remain anonymous. 
I have read and understand the foregoing information and agree to my child's participation in this study.

Signature

Date

If you experience problems that are the result of your participation in this study, please contact the Chair of Human Subjects Research Review Committee, Office of Research and Sponsored Projects, 105 Neuberger Hall, Portland State University, (503) 725-3417. 


\section{APPENDIX B}

Baseline and Probe Word List

\section{Consonant Sequences / Stridents}

\begin{tabular}{ll} 
Targeted Words: & Non-Targeted Words: \\
\hline spin & speech \\
spill & spell \\
spy & spa \\
spot & sport \\
spoon & spice \\
star & \\
stamp & storm \\
stool & still \\
stone & stew \\
stop & sting \\
& stage \\
smile & \\
smell & smooth \\
smooch & smash \\
small & smear \\
smurf & smart \\
\end{tabular}

Liquid/r/

Targeted Words:

Non-Targeted Words:

run

rain

red

ring

rose

row

read

race

write

rope

ear

bar

pour

tire

chair

air

jar

door

share

year

arrow

hurry

forest

marry

parrot

cherry

orange

arrive 
parade

worry

Velars

Targeted Words:

Non-Targeted Words:

key

cape

cop

can

cub

cave

cab

kite

kit

coin

\section{$\underline{\text { Liquid /1/ }}$}

Targeted Words:

Non-Targeted Words:

light

lip

leap

lay

lick

leaf

load

lamp

land

leg

bowl

pool

hole

mill

seal

tile

kneel

fall

nail

bell 
APPENDIX C

Baseline and Probe Schedule

\begin{tabular}{|c|c|c|}
\hline Date & Remediation Program & Baseline / Probe Administered \\
\hline $1 / 9 / 95$ & Pre-Test & All \\
\hline $1 / 11 / 95$ & Cycling & Consonant Sequences / Stridents \\
\hline $1 / 13 / 95$ & Cycling & Consonant Sequences / Stridents \\
\hline $1 / 18 / 95$ & Cycling & All \\
\hline $1 / 20 / 95$ & Cycling & Liquid /r/ \\
\hline $1 / 23 / 95$ & Cycling & Liquid / $\mathrm{r} /$ \\
\hline $1 / 25 / 95$ & & All \\
\hline $1 / 27 / 95$ & Minimal Pairs & Velars \\
\hline $1 / 30 / 95$ & Minimal Pairs & Velars \\
\hline $2 / 1 / 95$ & Minimal Pairs & Velars \\
\hline $2 / 3 / 95$ & Minimal Pairs & Velars \\
\hline $2 / 6 / 95$ & Minimal Pairs & Velars \\
\hline $2 / 8 / 95$ & & All \\
\hline $2 / 10 / 95$ & Cycling & Consonant Sequences / Stridents \\
\hline $2 / 15 / 95$ & Cycling & Consonant Sequences / Stridents \\
\hline $2 / 20 / 95$ & Cycling & All \\
\hline $2 / 22 / 95$ & Cycling & Liquid /r/ \\
\hline $2 / 24 / 95$ & Cycling & Liquid /r/ \\
\hline $2 / 27 / 95$ & & All \\
\hline $3 / 1 / 95$ & Minimal Pairs & Liquid /V \\
\hline $3 / 3 / 95$ & Minimal Pairs & Liquid /V \\
\hline $3 / 6 / 95$ & Minimal Pairs & Liquid /1/ \\
\hline $3 / 8 / 95$ & Minimal Pairs & Liquid /V \\
\hline $3 / 13 / 95$ & Minimal Pairs / Post-Test & All \\
\hline
\end{tabular}

